Muhammad Al Kholif, Teguh Yudha M, \& Sri Widyastuti : Tingkat Penyisihan Cemaran Air Sungai Menggunakan Coagulant Aid, Sediment Polypropylene, dan Manganese Greensand

\title{
TINGKAT PENYISIHAN CEMARAN AIR SUNGAI MENGGUNAKAN COAGULANT AID, SEDIMENT POLYPROPYLENE, DAN MANGANESE GREENSAND
}

\author{
Muhammad Al Kholif ${ }^{1)}$, Teguh Yudha Ma'fuddin' ${ }^{1)}$, dan Sri Widyastuti' ${ }^{1}$, \\ ${ }^{1)}$ Program Studi Teknik Lingkungan, Fakultas Teknik Sipil dan Perencanaan \\ Universitas PGRI Adi Buana Surabaya \\ Email Korespondesi : sriwidyastuti@unipasby.ac.id
}

\begin{abstract}
Abstrak
Air sungai merupakan salah satu sumber air bersih, namun air sungai telah banyak dicemari oleh limbah domestik maupun limbah cair industri, sehingga kualitas air sungai tidak memenuhi syarat kesehatan yang meliputi persyaratan fisika, kimia, dan mikrobiologi. Oleh sebab itu, air sungai harus diberikan perlakuan lebih lajut agar dapat memenuhi syarat baku mutu air bersih menurut Permenkes RI No.416/Menkes/Per/IX/1990. Penelitian ini bertujuan untuk mengetahui efisiensi penurunan kadar Total Dissolved Solids (TDS) dan Mangan (Mn) menggunakan sistem filtrasi Sediment Polypropylene dan Manganese Greensand dengan penambahan Succolite SP211 sebagai koagulan. Air baku yang digunakan adalah air Kali Surabaya. Variabel penelitian ini adalah debit air baku $1 \mathrm{~L} / m e n i t, 1,5 \mathrm{~L} / m e n i t$, dan $2 \mathrm{~L} / \mathrm{menit}$. Dari hasil penelitian efisiensi penurunan yang paling efektif yaitu debit $1 \mathrm{~L} /$ menit, yang mampu menurunkan parameter TDS lebih dari 60\% dan parameter Mn lebih dari $85 \%$.
\end{abstract}

Kata Kunci: Filtrasi, Succolite SP211, Sediment Polypropylene, Manganese Greensand

\begin{abstract}
River water is one of source of clean water, but river water has been heavily contaminated by a grey water or an industrial waste, so the river water quality does not meet requirements that involve physics, chemical and microbiology. That force, river water should be given more treatment to fulfill the quality standard of clean water according to Permenkes RI No.416/Menkes/Per/IX/1990. This study intend to know the effectivity of the reduction of Total Dissolved Solids (TDS) and Mangan (Mn) by using filtration system Sediment Polypropylene and Manganese Greensand with water addention of Succolite SP211 as a coagulant. Samples used come from Surabaya river. The variables of this study is the raw are water's debit $1 \mathrm{~L} / \mathrm{min}, 1,5 \mathrm{~L} / \mathrm{min}, 2 \mathrm{~L} / \mathrm{min}$. Based on the test study the most effective debit is $1 \mathrm{~L} / \mathrm{min}$, that can reduce TDS more than $60 \%$ and Mn more than $85 \%$.
\end{abstract}

Keywords: Filtration, Succolite SP211, Sediment Polypropylene, Manganese Greensand 

Air Sungai Menggunakan Coagulant Aid, Sediment Polypropylene, dan Manganese Greensand

\section{PENDAHULUAN}

Air bersih merupakan kebutuhan yang penting bagi makhluk hidup. Manusia, hewan, dan tumbuhan pasti membutuhkan air untuk kelangsungan hidup dan kebutuhan sehari-hari. Untuk menunjang kehidupan manusia saat ini banyak dibutuhkan air bersih, terutama di daerah perkotaan. Sumber air bersih yang banyak terdapat di daerah perkotaan yaitu air sungai. Beberapa daerah di Indonesia, terutama di daerah perkotaan banyak mengandalkan air sungai sebagai bahan baku kebutuhan air bersih. Menurut Purwoto (2017) air sungai juga menjadi bahan baku bagi Perusahaan Air Minum di Indonesia. Ini karena keterkaitan tiga hal yang saling mendukung, yaitu: 1) Jumlah cukup, 2) Kualitasnya lebih baik (dibanding air laut), dan 3) Fluktuasi laju alir relatif memenuhi keberlanjutan produksi. Kandungan lumpur, zat padatan terlarut (TDS), dan tingginya tingkat kekeruhan di air sungai merupakan masalah utama dalam hal pengolahan awal untuk keperluan air bersih. Kondisi air sungai Surabaya (saat dan lokasi tertentu) yaitu pH 6,33-7,51 dan TDS (Total Dissolved Solids) 200-1000 NTU, kekeruhan 71345 NTU, DO (Dissolve Oxygen) 4,5512,42 ppm, BOD (Biological Oxygen Demand) 6,241135 - 12,48227 ppm, COD (Chemical Oxygen Demand) 20$260 \mathrm{ppm}$. Kandungan besi (Fe) yaitu berada pada rentang 0,7486-39,2775 ppm sedangkan pada sedimen yaitu 16944,24 - 83096,96 ppm (Putri et al, 2015).

Air yang mengandung Total Dissolved Solids (TDS) tinggi, sangat tidak baik untuk kesehatan manusia. Mineral dalam air tidak hilang dengan cara direbus. Bila terlalu banyak mineral anorganik di dalam tubuh dan tidak dikeluarkan, maka seiring berjalannya waktu akan mengendap di dalam tubuh yang berakibat tersumbatnya bagian tubuh (Nugroho, 2013). Pada perairan dengan kondisi anaerob akibat dekomposisi bahan organik dengan kadar yang tinggi, $\mathrm{Mn}^{4+}$ pada senyawa mangan dioksida mengalami reduksi menjadi $\mathrm{Mn}^{2+}$ yang bersifat larut. $\mathrm{Mn}^{2+}$ berikatan dengan nitrit, sulfat, klorida, dan larut dalam air. Jika perairan kembali mendapat cukup aerasi, $\mathrm{Mn}^{2+}$ mengalami reoksidasi membentuk $\mathrm{Mn}^{4+}$ yang selanjutnya mengalami presipitasi dan mengendap di dasar perairan (Fahmi, 2012).

Salah satu perlakuan untuk menurunkan kandungan TDS dan Mn adalah dengan menggunakan teknologi berupa pengolahan air dengan treatment : Coagulant Aid, Sediment Polypropylene (SPP), dan Manganese Greensand. Koagulan yang dapat digunakan pada instalasi pengolahan air diantaranya adalah Succolite SP 211. Succolite berbentuk cairan, tidak berwarna dan tidak berbau. Succolite mempunyai $\mathrm{pH}$ pada suhu $20^{\circ} \mathrm{C}$ sebesar 11-11,5 selain itu cairan ini mempunyai berat jenis $1,35 \mathrm{gr} / \mathrm{cm}^{3}$. Sediment Polypropylene berfungsi untuk menyaring air dari kandungan lumpur, pasir, tanah dan partikel kotoran zat padat terlarut dalam air lainnya sehingga menghasilkan air jernih, bersih bebas dari pencemaran zat padat terlarut dalam air. Sediment Polypropylene mempunyai removal ratings : $0.2,0.45$, $1,5,10,20,50 \mu \mathrm{m}$. Dengan suhu maksimum $82{ }^{\circ} \mathrm{C}$, dan rekomendasi tekanannya adalah 35 psig (Nurhayati, 2014a). Manganese Greensand merupakan absorben untuk menurunkan kadar besi dan mangan pada air. Dimana reaksi dari $\mathrm{Fe}^{2+}$ dan $\mathrm{Mn}^{2+}$ dalam air dengan oksida mangan tinggi (Higher Mangan Oxide) menghasilkan filtrat yang mengandung ferri-oksida dan mangan-oksida yang tidak dapat larut dalam air dan dapat dipisahkan dengan pengendapan dan penyaringan. removal $\mathrm{Mn}^{2+}$ dapat dilakukan dengan adsorbsi oleh Mangan oksida dalam Manganese Oxide Coated Zeolite (MOCZ) (Taffarel, 2010).

Tujuan dari penelitian ini adalah untuk mengetahui besar efisiensi penurunan parameter TDS dan Mn dalam air sungai dengan menggunakan 
Muhammad Al Kholif, Teguh Yudha M, \& Sri Widyastuti : Tingkat Penyisihan Cemaran Air Sungai Menggunakan Coagulant Aid, Sediment Polypropylene, dan Manganese Greensand

pengolahan Coagulant Aid, SPP, dan Manganese Greensand. Penelitian terdahulu menggunakan filtrasi Manganese Greensand terpadukan resin memiliki efektivitas removal kadar Mn sebesar 93,97\% (Qaswaini, 2017). Sedangkan efektivitas removal kadar TDS menggunakan treatment Succolite SP211, Sediment Polypropylene, Manganese Greensand, resin penukar ion, dan membran Reverse Osmosis (RO) yaitu sebesar 90,8\% (Nurhayati, 2014a). Purwoto et al. (2014) menyimpulkan bahwa removal parameter air bersih menggunakan treatment Sediment PolyPropylene, Carbon Block, Manganese Zeolite, IonExchange, dan Reverse Osmosis (RO) adalah : Total Disolved Solid (TDS) 2686ppm, kesadahan total 371.43 mg/L CaCO3, klorida 1144 ppm, Total Coliform 4 MPN/100mL, Besi 0.18 ppm, Natrium 737.70 ppm, Seng 0.08 ppm, Sulfat $24.56 \mathrm{ppm}$, senyawa organik $15.03 \mathrm{mg} / \mathrm{L} \quad \mathrm{KMnO} 4$, dan detergen $0.10 \mathrm{mg} / \mathrm{L}$ LAS.

Pada pengolahan air sungai menggunakan treatment Coagulant Aid, pasir silika, Ferrolite, Manganese Greensand, dan resin sintetis (anion kation) dapat menurunkan parameter air bersih antara lain: Kekeruhan 148,02 Skala NTU, Warna 148 PtCo Unit, Besi $8,74 \mathrm{mg} / \mathrm{L} \mathrm{Fe}$, kesadahan total 35,71 $\mathrm{mg} / \mathrm{L} \mathrm{CaCO} 3$, Zinc $0,03 \mathrm{mg} / \mathrm{L} \mathrm{Zn}$, Bahan Organik 12,79 Mg/L KMnO4, deterjen $0,26 \mathrm{mg} / \mathrm{L}$ LAS, Total Coliform 1,6983 juta Jumlah per $100 \mathrm{~mL}$ (MPN) (Purwoto, 2017).

Pada penelitian ini teknologi yang digunakan oleh peneliti diharapkan mampu menurunkan kadar TDS dan Mn pada air sungai secara signifikan. Alasan dipilih Succolite SP211 karena efisiensi pemakaian fasa cair. Dipilihnya Manganese Greensand karena biaya cukup murah, bebas dari bahan kimia berbahaya pada efluennya, dan sederhana dalam pengoperasian. Sedangkan Sediment Polypropylene dipilih karena praktis, mudah didapat, dan daya filter tinggi (Purwoto, 2016).

\section{METODE}

Rancangan penelitian dalam penelitian ini diawali dengan pengambilan sampel air baku, kemudian dilakukan pengolahan menggunakan Coagulant Aid pada tandon air baku. Kemudian dilanjutkan dengan menggunakan pengolahan Sediment Polypropylene dan diakhiri dengan menggunakan pengolahan Manganese Greensand.

Variable air baku yang diterapkan dalam penelitian yaitu $1 \mathrm{~L} /$ menit, 1,5 $\mathrm{L} /$ menit, dan $2 \mathrm{~L} / \mathrm{menit}$ dengan sampel penelitian yang digunakan adalah air Kali Surabaya. Secara lengkap rangkaian alat penelitian disajikan dalam gambar 1 berikut.

Alat dan bahan yang digunakan dalam penelitian ini adalah :

a. Bahan reaktor yang digunakan catridge filter housing. Fungsi housing filter adalah untuk menempatkan cartridge filter (katrid filter) yang mana dalam proses penyaringan air maka cartridge filter tidak dapat berdiri sendiri sehingga diperlukan housing filter sebagai rumahnya.

b. Untuk memudahkan setting dan efisiensi aliran, pipa yang digunakan PVC, dengan setting sambungan water-mur.

c. Pompa supplay menggunakan submersible-pump bahan plastik guna menghindari korosi.

d. Succolite SP 211 yang berfungsi mempercepat sedimentasi oleh kinerja koagulasi.

e. Sediment Polypropylene berfungsi sebagai filtrasi suspense, koloid, dan partikel diskrit.

f. Manganese Greensand untuk menghilangkan kandungan Mangan $\left(\mathrm{Mn}^{2+}\right)$, dan lapisan atas berminyak di dalam air sebagai katalis dan pada waktu yang bersamaan besi dan mangan yang ada dalam air teroksidasi menjadi bentuk ferrioksida dan mangandioksida yang tak larut dalam air. 


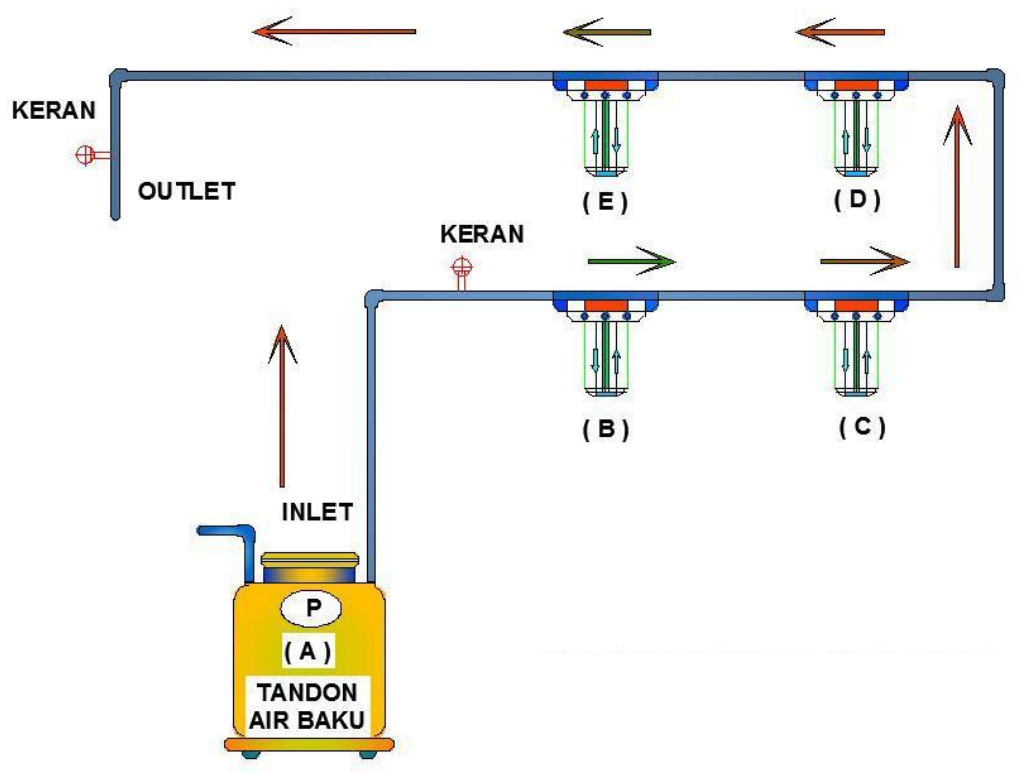

Gambar 1. Rancangan Treatment Air Sungai

Keterangan Gambar 1: Coagulant Aid pada tandon air baku olahan
(A) : $\quad$ Penambahan
(B) :
Polypropylene pada catridge filter dalam tabung housing filter
(C) : treatment Manganese Greensand pada catridge filter dalam tabung housing filter
(D) : $\quad$ Sediment
Polypropylene pada catridge filter dalam tabung housing filter
(E) : treatment Manganese Greensand pada catridge filter dalam tabung housing filter
(P) : Submersible Pump

Langkah-langkah dalam penelitian ini adalah :

a. Debit yang digunakan dalam penelitian ini adalah $1 \mathrm{~L} /$ menit, 1,5 $\mathrm{L} /$ menit, $2 \mathrm{~L} /$ menit. Debit yang diatur dilakukan dengan cara manual yaitu Trial Error. b. Air baku ditampung dalam tandon air, selanjutnya dilakukan penambahan Succolite SP211 sebagai Coagulant Aid. Penambahan Succolite SP 211 yaitu sebesar 90 ppm.

c. Kemudian air baku dipompa menggunakan submersible-pump menuju filtrasi Sediment Polypropylene sebagai cartridge pada housing filter (B), dilanjutkan treatment Manganese Greensand pada catridge filter dalam housing filter (C), berikutnya berturut-turut treatment Sediment Polypropylene, treatment Manganese Greensand yang dirangkai secara seri. Dilakukan susunan catridge seperti itu dikarenakan Sediment Polypropylene berfungsi menyaring air dari kandungan lumpur, pasir, tanah dan partikel kotoran zat padat terlarut dalam air.

d. Model aliran dalam penelitian ini adalah up-flow. Lama waktu pengaliran air baku dalam penelitian ini adalah 30 menit per sampel.

e. Material yang digunakan untuk treatment harus dicuci terlebih dahulu. 
Muhammad Al Kholif, Teguh Yudha M, \& Sri Widyastuti : Tingkat Penyisihan Cemaran Air Sungai Menggunakan Coagulant Aid, Sediment Polypropylene, dan Manganese Greensand

f. Sampel air hasil olahan dianalisis dengan menggunakan metode penelitian air untuk menguji parameter air bersih.

g. Replikasi dilakukan sebanyak 2 kali. Setiap pengulangan seluruh media yang terdapat pada instalasi diganti dengan media yang baru. Hal ini bertujuan untuk mencegah terjadinya kejenuhan pada media yang dapat menyebabkan turunnya efisiensi penurunan.

Analisis data yang digunakan adalah persen removal (\% removal), yaitu untuk mengetahui seberapa besar penurunan parameter-parameter terkandung dalam air baku. Metode yang digunakan dalam analisis data ini yaitu analisis secara tabel dan grafik kemudian dijelaskan dengan jalan membandingkan antar variasi debit. Data yang diperoleh merupakan data dari hasil pengujian yang dilakukan di Laboratorium Politeknik Kesehatan Kemenkes Surabaya dan Laboratorium Kualitas Lingkungan Institut Teknologi Sepuluh Nopember (ITS) Surabaya.

\section{HASIL DAN PEMBAHASAN Efisiensi Penurunan Parameter TDS} Total Dissolved Solids (TDS) atau Padatan Terlarut Total adalah bahanbahan terlarut (diameter $<10^{-6} \mathrm{~mm}$ ) dan koloid (diameter $10^{-6} \mathrm{~mm}-10^{-3} \mathrm{~mm}$ ) yang berupa senyawa-senyawa kimia dan bahan-bahan lain yang tidak tersaring pada kertas saring berdiameter 0,45 $\mu \mathrm{m}$ (Rao dalam Effendi, 2003). Air dengan TDS tinggi memiliki rasa yang buruk atau tidak enak. Selain itu, perubahan konsentrasi TDS dapat berbahaya karena berhubungan dengan massa jenis air. Massa jenis air menentukan aliran air masuk dan keluar dari sel-sel organisme. Jika konsentrasi terlalu tinggi kejernihan air akan menurun dan menghambat fotosintesis dan memungkinkan terjadi gabungan senyawa beracun dan logam berat akan meningkatkan suhu air (Effendi, 2003). Efisiensi penurunan parameter TDS seperti tersaji pada gambar 2 .

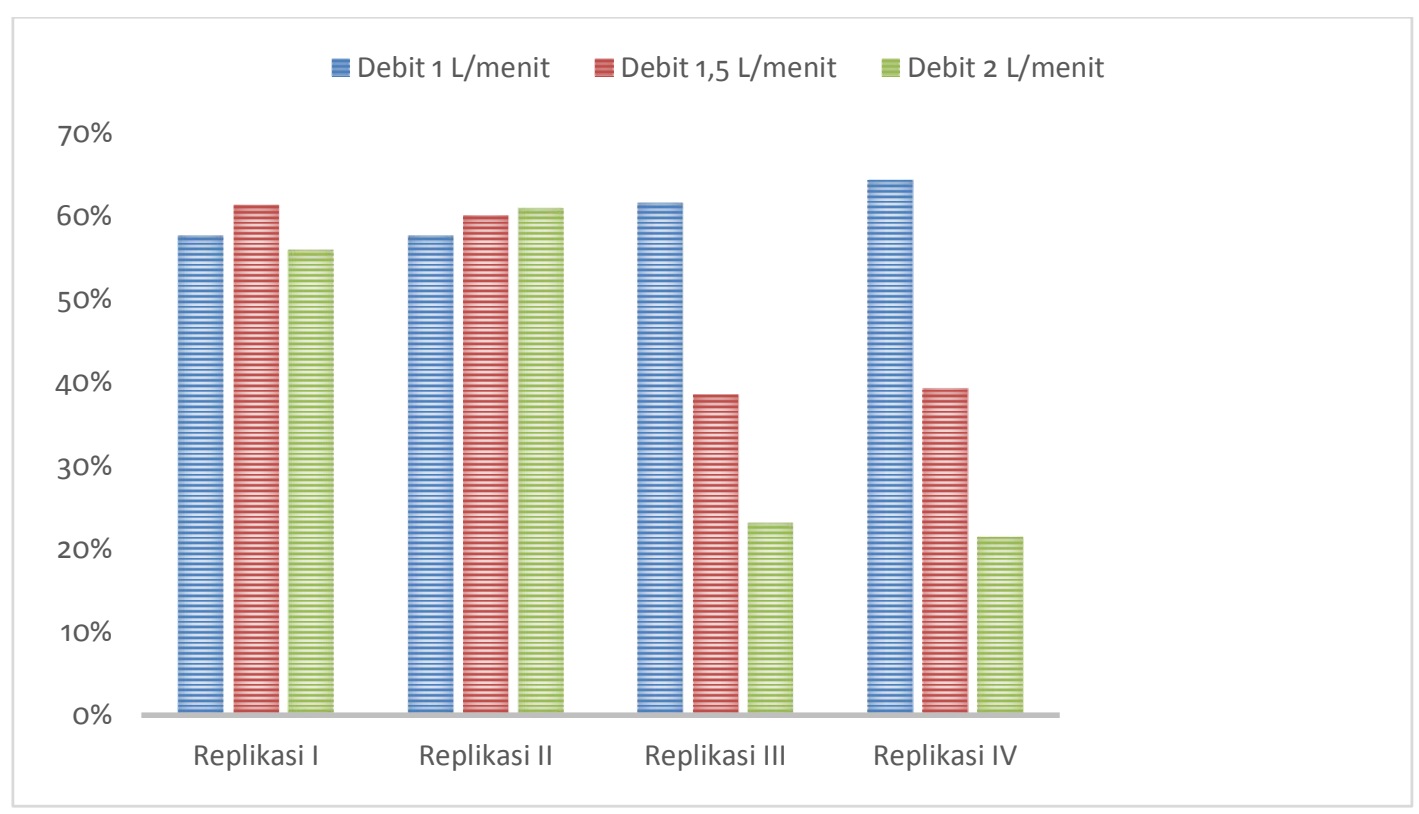

Gambar 2. Efisiensi Penurunan Kadar TDS

Dari gambar 2 (Grafik Efisiensi Penurunan kadar TDS) dapat dilihat bahwa efisiensi penurunan kadar TDS paling tinggi dihasilkan dari debit 1
L/menit yaitu pada replikasi IV yang mampu menurunkan kadar TDS sebesar 64\%. Kadar TDS air baku sebelum treatment yaitu $1400 \mathrm{mg} / \mathrm{L}$. Setelah 
Muhammad Alkholif, Teguh Yudha M, \& Sri Widyastuti : Tingkat Penyisihan Cemaran Air Sungai Menggunakan Coagulant Aid, Sediment Polypropylene, dan Manganese Greensand

mengalami treatment menjadi 500 $\mathrm{mg} / \mathrm{L}$. Sedangkan efisiensi penurunan kadar TDS paling rendah dihasilkan dari debit $2 \mathrm{~L} /$ menit yaitu pada replikasi IV yang mampu menurunkan kadar TDS sebesar $21 \%$. Kadar TDS awal yaitu $1400 \mathrm{mg} / \mathrm{L}$, setelah mengalami treatment menjadi $1100 \mathrm{mg} / \mathrm{L}$.

Dapat dikatakan bahwa semakin tinggi debit aliran, semakin rendah penurunannya. Namun ini tidak berlaku pada kadar TDS yang rendah, tidak ada perbedaan yang signifikan antar debit pada penurunan kadar TDS. Debit yang paling efektif dalam menurunkan kadar TDS yaitu debit 1 L/menit yang mencapai $64 \%$. Dapat dikatakan bahwa pada kadar TDS yang rendah tidak ada pengaruh debit, sedangkan pada kadar TDS yang tinggi terjadi pengaruh debit.

Removal parameter air bersih oleh perpaduan treatment Coagulant Aid, filtrasi Sediment Polypropylene (SPP), Manganese Greensand, dilanjutkan dengan Ion Exchanger, dan membran RO memenuhi persyaratan air bersih yang mampu menurunkan kandungan TDS sebesar $82 \%$ (Nurhayati, 2014b). Hasil yang didapatkan tidak sebesar pada penelitian sebelumnya, hal ini dikarenakan tidak adanya pengolahan menggunakan Ion Exchange, dan Reverse Osmosis (RO). Penyisihan kadar TDS lebih maksimal karena adanya treatment menggunakan Reverse Osmosis. Reverse Osmosis memiliki membran semi permeabel yang dapat menyisihkan kadar TDS yang tidak dapat dihilangkan pada treatment sebelumnya. Meskipun hasil yang didapat tidak sebesar pada penelitian sebelumnya, tetapi sudah dapat memenuhi persyaratan baku mutu untuk TDS yang ditetapkan Permenkes Nomor 416 Tahun 1990.

\section{Efisiensi Penurunan Parameter Mn}

Mn merupakan unsur logam golongan VII. Di dalam hubungannya dengan kualitas air yang sering dijumpai adalah senyawa mangan dengan valensi 2 , valensi 4 , valensi 6 . dalam senyawa $\mathrm{MnCO}_{3}, \mathrm{Mn}(\mathrm{OH})_{2}$ mempunyai valensi dua, zat tersebut relatif sulit larut dalam air, tetapi untuk senyawa $\mathrm{Mn}$ seperti garam $\mathrm{MnCl}_{2}, \quad \mathrm{MnSO}_{4}, \quad \mathrm{Mn}\left(\mathrm{NO}_{3}\right)_{2}$ mempunyai kelarutan yang besar di dalam air. Mn dalam air dapat menimbulkan bau dan rasa yang tidak sedap (Said, 2011). Efisiensi penurunan Mn seperti tersaji pada gamabr 3.

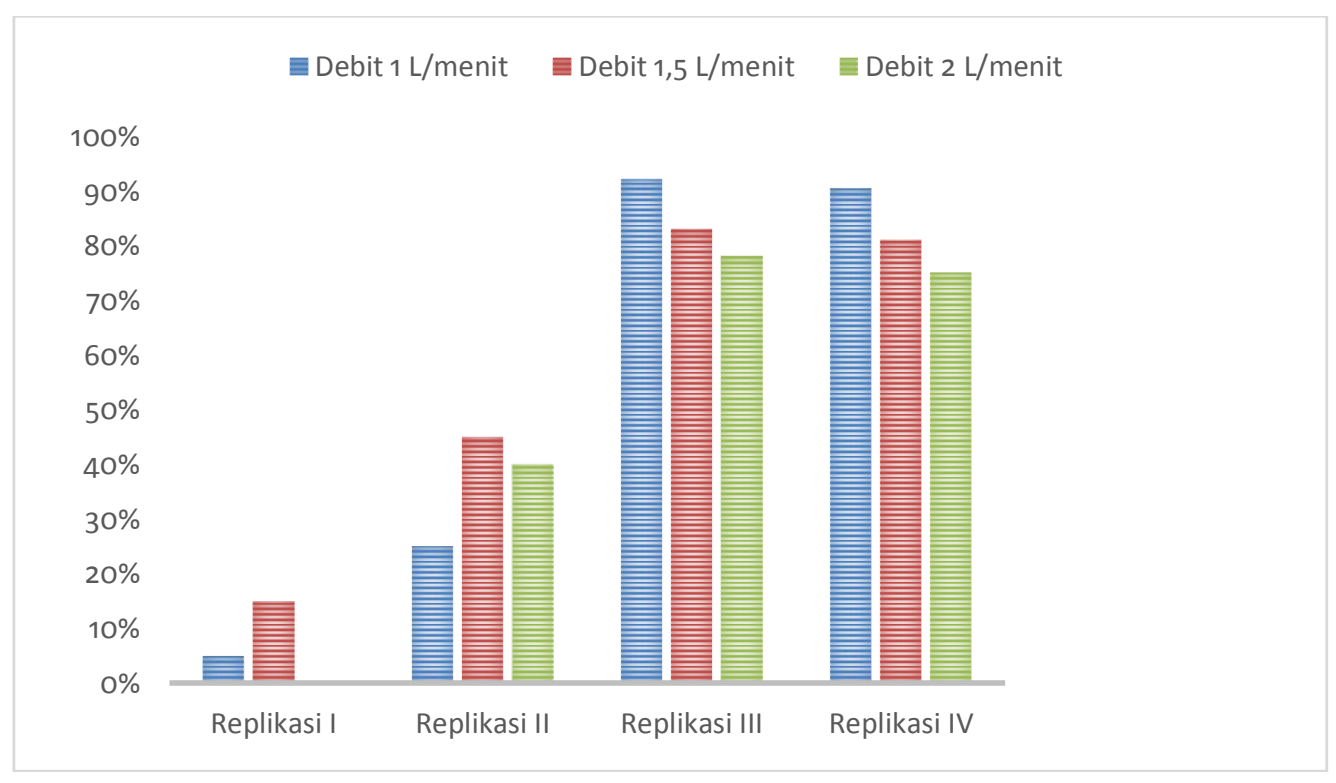

Gambar 3. Efisiensi Penurunan Kadar Mn 
Dari gambar 3 (Grafik Efisiensi Penurunan Kadar Mn) di atas dapat dilihat bahwa penurunan kadar Mn paling tinggi dihasilkan dari debit 1 L/menit yaitu pada replikasi III yang mampu menurunkan kadar Mn sebesar 92\%, Kadar Mn sebelum treatment yaitu $1,65 \mathrm{mg} / \mathrm{L}$. Setelah mengalami treatment menjadi $0,13 \mathrm{mg} / \mathrm{L}$.

Sedangkan penurunan kadar Mn paling rendah dihasilkan dari debit 2 $\mathrm{L} / \mathrm{menit}$ yaitu pada replikasi I yang tidak dapat menurunkan kadar Mn. Artinya kadar Mn sebelum dan sesudah treatment kadarnya sama. Hasil yang tidak stabil dari penurunan kadar Mn dapat disebabkan oleh beberapa faktor. Salah satu faktor yaitu pada replikasi I dan II sempat terjadi penyumbatan pada saat proses treatment yang mempengaruhi kinerja filter dan media penyaring, sehingga media tidak dapat bekerja dengan optimal. Debit yang paling efektif dalam menurunkan kadar Mn yaitu debit $1 \mathrm{~L} /$ menit yang mencapai 92\%. Hal ini menunjukkan bahwa semakin tinggi debit aliran, semakin rendah penurunannya.

Efisiensi penuruan kadar $\mathrm{Mn}$ menggunakan media Manganese Greensand terpadukan resin penukar ion adalah 99\% (Rahmawati, 2016). Hasil yang didapatkan tidak sebesar pada penelitian sebelumnya, hal ini dikarenakan tidak ada pengolahan lebih lanjut menggunakan resin penukar ion. Proses pertukaran ion melibatkan reaksi kimia antara ion dalam fasa cair dengan ion dalam fasa padat. Ion-ion tertentu dalam larutan lebih mudah terserap oleh solid penukar ion, dan karena elektronetralitas harus dijaga, solid penukar melepas ion dan dipertukarkan ion dalam larutan. Dalam proses demineralisasi, maka sebagai contoh: kation $\mathrm{Na}^{+}$dan anion $\mathrm{Cl}^{-}$disisihkan dari air dan solid resin melepas ion $\mathrm{H}^{+}$untuk ditukar dengan ion $\mathrm{Na}^{+}$, serta $\mathrm{OH}^{-}$ ditukar dengan $\mathrm{Cl}^{-}$dari air sehingga kandungan $\mathrm{Na}^{+}$dan $\mathrm{Cl}^{-}$dalam air menjadi berkurang atau hilang (Lee,
2005). Meskipun hasil yang didapat tidak sebesar pada penelitian sebelumnya, tetapi sudah dapat memenuhi persyaratan baku mutu untuk TDS yang ditetapkan Permenkes Nomor 416 Tahun 1990. Mengacu pada temuan Rachmah, N dan Purwoto, S (2014) filter zeolit alam Manganese Green Sand dan zeolit teraktivasi dengan pemanasan, dimana reaktor yang digunakan memiliki ukuran tinggi 100 $\mathrm{cm}$, kedalaman media $60 \mathrm{~cm}$, diameter zeolit alam mess 16-7, diameter manganese green sand mess 30-12 dan diameter zeolit teraktivasi dengan pemanasan mess 16-7 diperoleh penurunan kandungan $\mathrm{Mn}$ rata-rata sebesar $0,099 \mathrm{mg} / \mathrm{L}$ dari $2,53 \mathrm{mg} / \mathrm{L}$. terdapat perbedaan kemampuan removal Mn dengan penelitian tersebut karena adanya perbedaan perlakuan.

\section{KESIMPULAN}

Efisiensi penurunan TDS dan Mn yang paling efektif yaitu terjadi pada debit $1 \mathrm{~L} /$ menit. Hal ini dikarenakan semakin kecil debit aliran, maka semakin lama waktu kontak antara air baku dengan media, sehingga semakin besar efektivitas penurunannya. Debit 1 $\mathrm{L} /$ menit mampu menurunkan parameter TDS hingga $64 \%$ dan parameter $\mathrm{Mn}$ hingga 92\%. Kadar TDS air baku sebelum treatment yaitu $1400 \mathrm{mg} / \mathrm{L}$, setelah mengalami treatment menjadi $500 \mathrm{mg} / \mathrm{L}$. Sedangkan kadar Mn sebelum treatment yaitu $1,65 \mathrm{mg} / \mathrm{L}$, setelah mengalami treatment menjadi $0,13 \mathrm{mg} / \mathrm{L}$.

\section{UCAPAN TERIMA KASIH}

Ucapan terima kasih disampaikan kepada Setyo Purwoto yang telah banyak membantu dalam penelitian dan memfasilitasi dalam penggunaan alat pengolahan air baku serta kepala laboratorium Teknik Lingkungan Universitas PGRI Adi Buana (UNIPA) Surabaya atas fasilitas yang sudah disediakan selama penelitian. 
Muhammad Alkholif, Teguh Yudha M, \& Sri Widyastuti : Tingkat Penyisihan Cemaran Air Sungai Menggunakan Coagulant Aid, Sediment Polypropylene, dan Manganese Greensand

\section{DAFTAR PUSTAKA}

Effendi, H.(2003). Telaah Kualitas Air Bagi Pengelolaan Sumber Daya dan Lingkungan Perairan. Yogyakarta: Kanisius.

Fahmi, A. N., 2012. "Pengaruh Variasi Debit Terhadap Efisiensi Penurunan Konsentrasi Besi dan Mangan pada Air Sumur Gali dengan Menggunakan Teknik Saringan Pasir Aktif." Program Studi S-1 Ilmu dan Teknologi Lingkungan, Departemen Biologi, Fakultas Sains dan Teknologi, Universitas Airlangga.

Indonesia, Permenkes. (1990). PersyaratanAir Bersih, Nomor: 416/Menkes/Per/IX/199.

Lee, C.C.,Lin, S.D., (2005). Handbook of Environmental Engineering. McGraw-Hill Publishing, Tokyo.

Nugroho, W., Purwoto, S. (2013). "Removal Klorida, TDS dan Besi pada Air Payau Melalui Penukar Ion dan Filtrasi Campuran Zeolit Aktif dengan Karbon Aktif." Jurnal Teknik WAKTU Volume 11 Nomor 01 - Januari 2013 - ISSN: 1412-1867.

Nurhayati, I., Purwoto, S. (2014a). "Pengolahan Air Payau Berbasis Kimiawi melalui Tekno Membran Reverse Osmosis (RO) Terpadukan dengan Koagulan dan Penukaran Ion.” Prosiding Seminar Nasional Kimia, ISBN: 978-602-0951-00-3.

Nurhayati, I., Purwoto, S. (2014b). "The Combination of Coagulant Aid, Ion Exchanger, and Reverse Osmosis (RO) on Brackish Water Treatment." Journal of Natural Sciences Research, ISSN 2224-3186 (Paper); ISSN 2225-0921 (Online) 4(24): 2630.

Purwoto, S., Purwanto, T., \& Hakim, L. (2016). "Penjernihan Air Sungai Dengan Perlakuan Koagulasi, Filtrasi, Absorbsi dan Pertukaran Ion." WAKTU, 13(2), 4553.

Purwoto, S., Sopandi, T., Kusuma, P.S.W., \& Nurcahyanie, Y.D. (2014), "Removal Parameters of Clean Water using Treatment; Sediment PolyPropylene, CarbonBlock, Manganese Zeolite, Ion Exchange, and Reverse Osmosis(RO)." Journal of Environment and Earth Science 4(23),72- 77

Purwoto, S., Sutrisno, J. (2017), "Decreasing of Multiple Clean Water Parameters in River Water Treatment" Journal of Civil and Environmental Research 9(7), 1-6.

Putri, A. D. N., Utomo, Y., \& Kusumaningrum, I. K. (2013). "Analisis Kandungan Besi Di Badan Air Dan Sedimen Sungai Surabaya." Jurusan Kimia. FMIPA. Universitas Negeri Malang. Malang.

Qaswaini, A. (2017). "Penurunan Kadar Mangan (Mn) dalam air menggunakan Manganese Greensand dan Zeolit Terpadukan Resin." Tugas Akhir Sarjana Universitas Hasanuddin, Makassar.

Rachmah, N dan Purwoto, S. (2014). "Efektifitas Penurunan Mn dan Total Coliform pada Air Sumur Gali Berbasis Zeolit". Jurnal WAKTU 12 (01) Halaman 1-7

Rahmawati, N., Sugito, S. (2016). "Reduksi Besi (Fe) dan Mangan (Mn) Pada Air Tanah Menggunakan Media Filtrasi Manganese Greensand dan Zeolit Terpadukan Resin." WAKTU, 13(2), 63-71.

Said, N. I. (2011). "Metoda Penghilangan Zat Besi dan Mangan di dalam Penyediaan Air Minum Domestik." Jurnal Air Indonesia, 1(3).

Taffarel , S. R., Rubio, J. (2010). "Removal of $\mathrm{Mn}^{2+}$ from Aqueous Solution by Manganese Oxide Coated Zeolite." Minerals Engineering 23(14): 1131-1138. 